\title{
Rehabilitation of apartial maxillectomy patient with silicone relined hollow bulb obturator - Case report
}

\author{
Parthasarathy Natarajan ${ }^{1}$, C.Ramasamy ${ }^{2}$, T. V. Padmanabhan ${ }^{3}$ \\ **Senior Lecturer - Faculty of Dental Sciences, Sri Ramachandra University, Porur, Chennai, India. \\ ***Lecturer-Faculty of Dentistry, AIMST University, Semeling 08100, Bedong, Kedah DarulAman, Malaysia. \\ ****Professor \& Head of Department- Faculty of Dental Sciences, Sri Ramachandra University, Porur, \\ Chennai, India.
}

\begin{abstract}
Maxillary resection results in a discontinuity of the oral nasal and maxillary sinus cavities. Defect of any extent results in significant disabilities experienced by the patient. This may be manifested as difficulties in speech, mastication and esthetics. Prosthetic rehabilitation in the form of a palatal obturator is usually required to cover the defect and restore normal functions. In the cases of edentulous patients application of anobturator becomes even more cumbersome as the mechanism of retention is compromised.Achieving peripheral seal is questionable. In the present case, palatal defect is rehabilitated with silicone relined hollow bulb obturator. The portrayed obturator reduces the redundant load on the supporting tissue and provides a functional solution to the compromised state of the patient.
\end{abstract}

Key words: Maxillary defect, Hollow maxillary obturator, Silicone lining,Lost salt technique

\section{Introduction}

Tumors of the maxilla can cause abnormal and malignant changes to the tissues, which may require surgical excision. This result inan anatomic defect establishing a connection between the oral cavity, maxillary sinus and the nasal cavity. ${ }^{1}$ In case of patients with palatal insufficiency, deglutition and hypernasal tone becomes burdensome; therefore it is essential to provide treatment to such patients by means of an obturator.An obturator will provide an artificial barrier between the connected cavities and thereby enhancing the functional capabilities of speech, mastication and deglutition. ${ }^{2}$

The objective of the maxillary obturator is to restore the partition, restore palatal contour, replace the necessary dentition and in turn create a socially acceptable individual. Acceptable prosthodontic rehabilitation involves cautious prosthesis designing, along with regular review and good care to provide function, esthetics and minimal damage to underlying compromised structure. In completely edentulous cases, it is mandatory to keep in mind the remaining supporting tissues while replacing what is lost. A comprehensive technique of restoring palatal defect with one piece closed hollow bulb obturator with silicone lining is illustrated here.

\section{Case Report}

Here, presenting a prosthetic rehabilitation of maxillectomy patient, a 61 year old female reported to department of prosthodontics, for prosthetic rehabilitation. Her chief complaint was inability to eat and poor esthetics. Past medical history revealed that, she underwent partial maxillectomy as surgical plan for inflammatory lesion of right maxilla and nasal cavity with secondary mucoid degeneration. On extra oral examination, the right side of the cheek appeared shrunken. The intra oral examination revealed partially edentulous maxilla and mandible with palatal defect on right side (figure1). Third molar was the only tooth present in left side of the maxilla. The patient was reluctant in getting her mobile mandibular anterior teeth extracted. The prognosis of the mandibular partial denture was explained to the patient before the execution of the treatment. Considering retention and stability of the prosthesis, silicone relined one piece closed hollow bulbdefinitive obturatorwas planned to accomplish the patient's need.

\section{Procedure}

The primary impression of maxillary defect area was made with impression compound (DPI- pinnacle) and it was picked with alginate (DPI- Algitex) impression using stock tray.Care was taken to block the undercut with moisten gauze. Dental floss was tied to the gauze to avoid intrusion of the impression material and further injuries.Using primary cast,the special tray was fabricated.Border mouldingwas done with low fusing impression compound (DPI- tracing ticks) and final impression taken with medium body addition silicone impression material (Aquasil- Dentsply). Master cast was poured with type III gypsum product. The undercuts in the bulb portion of the master cast were blocked with modelling wax (DPI) and record base was constructed with auto-polymerization resin (DPI -RR Cold Cure). Themaxilla-mandibular jaw relation was recorded\& inter ridge distance was found to be more. The teeth selectionwas performed according to patient's age, sex and 
personality and the semi anatomic teeth form was used. Waxed trial denture insertion verified the recorded jaw relation and teeth arrangement. The conventional flasking procedure was performed. After de-waxing, undercut present in the defect area was sealed with clay material (figure 2). One layer of heat cure acrylic resin (DPI) of thickness $1.5 \mathrm{~mm}$ was placed over the defect \&adjacent ridge area of the cast. The common table salt $(\mathrm{NaCl}) \mathrm{was}$ used to fill the defect area.Over the salt, putty consistency vinyl polysiloxane impression material (Express-3MESPE) was placedin the shape of residual ridge and adapted with soft pressure (figure 3)\& itwas further covered with a layer of heat cure acrylic resin (figure 4). Routine packing of acrylic resin \& curing of the prosthesis was done. After de-flasking, the maxillary denture was retrieved. The hole was created in the posterior end of maxillary tuberosity region on the polished side of the denture to remove the putty and salt (figure 5). Later the hole was sealed with self-cure acrylic resin (DPI - RR Cold Cure).

The finished prosthesis of single piece hollow bulb obturator was tried in the patient mouth. Meticulous care had been taken during obturator fit $-\mathrm{in}$, and assured that the sharp borders were smoothened. The permanent silicone relining material (GC Reline extra soft) was incorporated to the tissue surface of the bulb portion of the obturator and it was checkedintraorally (Figure 6). When the silicone sets, obturator was removed and excesssilicone was removed with scissors. The obturator was re-inserted and the seal, retention \& stability were evaluated (figure 7). The patient was called after a day; a week and month for review and the retention of the prosthesis was found to be satisfactory. The prognosis of the mandibular partial denture was emphasized to the patient in her reviews.

\section{Discussion}

Rehabilitation of palatal deficiency patients requires restoration of mastication, deglutition and speech. Considering the patient's condition and economic background, the prosthesis was fabricated according to her needs. Third molar tooth of left side of the maxillary arch was used for retention of the prosthesis through wrought alloy clasp. The weight of prosthesis was often a dislodging factor that has to be considered ${ }^{3,4}$. Weight reduction was cardinal when the obturator prosthesis was suspended without bony or posterior tooth support on the defect $\operatorname{side}^{5}$. The weight of the prosthesis can be reduced up to $33 \%$ when obturator is fabricated hollow ${ }^{6}$.

Pertaining to the fabrication of obturators, controversies do exist between the closed and open hollow bulb obturators. The closed hollow bulb obturator prosthesis can prevent food and fluid collection; minimizes the air space and favors for maximum extension ${ }^{7}$. The open hollow bulb obturator has the problem of collectingmucous and fluids and need frequent cleanings or a vent placement to eliminate accumulation in the bulb ${ }^{8}$. Literature reveals that, numerous materials have been put forth for fabrication of hollow bulb obturator. They include cellophane wrapped asbestos 9 , putty consistency elastomer ${ }^{10}$, modeling clay ${ }^{11}$, plasterindex ${ }^{12}$, salt ${ }^{13}$ or thermoplastic splint material ${ }^{14}$.Parel et $\mathrm{al}^{15}$, Schneider ${ }^{16}$ have used ice, sugar in the defect portion during processing and later removed by creating holes after processing.El Mahdy ${ }^{17}$ used double-flask technique for fabrication of the hollow bulb obturator. But these techniques requiremore laboratory steps, like processing of the obturator bulb and the dentulous area separately. Likewise McAndrewet al ${ }^{18}$ acquainted an investment method, which requires multiple flasks for fabrication of closed bulb obturator. On the contrary, this procedure had dimensional changes during processing. Tanaka etal ${ }^{19}$ used polyurethane foam as core material to reduce the weight of the obturator.Consequently, their methodhad the disadvantages of uneven thickness in the hollow bulb obturator walls and also adds more weight to the obturator.In the present scenario, the heat cure acrylic resin of even thickness was placed in the defect area during packing to ensure that thickness of the obturator wall was maintained. With the increased inter ridge distance in the incumbent situation; extending hollowness to ridge part was desirable.Hence, salt $(\mathrm{NaCl}) \&$ putty silicone were used to fabricate hollow bulb. The salt was employed for bulb portion and the silicone putty was utilized for ridge area. Considering the difficulty in retrieving silicone putty in bulb portion, salt was preferred and silicone putty for ridge portion. Moreover, salt is not retained in ridge part during processing and due to the consistency of silicone putty, it remained stable. Silicone relining material can be utilized to engage the undercut and it also relieves the pressure during function ${ }^{20}$. Here a portion of obturator was made resilient so that silicone material appropriately engages the undercut present to aid in relatively better retention and stability, which a rigid obturator fails to provide ${ }^{21}$. The portrayed obturator reduces the redundant load on the supporting tissue and meets the patient demands.

\section{Conclusion}

The rehabilitation of patients with defects of the maxilla with hollow bulb obturators with silicone relining provides a means of enhancing the retention and stability of the prosthesis. Such designed prosthesis provides a functional solution to the compromised state of the patient. 


\section{References}

[1] Spiro RH, Strong EW, Shah JP: Maxillectomy and its classification. Head Neck 1997;19:309-314

[2] Varoujan A. Chalian, Joe B. Drane [and] S. Miles Standish. Maxillofacial prosthetics, Williams \& Wilkins Co. Baltimore 1972 pp.133-157.

[3] Beumer J, Curtis TA, FirtellDN (1979) Speech, palatopharyngeal function, and restoration of soft palate defects. In: Maxillofacial rehabilitation-Prosthodontic and surgical considerations. C. V. Mosby Company, St Louis, pp 249, 267.

[4] V.A. Chalian and M.O. Barnett J. A new technique for constructing a one-piece hollow obturator after partial maxillectomy Prosthet Dent Oct1972; vol 28(4) 448-453.

[5] Parr GR, Tharp GE, Rahn AO. Prosthodontic principles in the framework design of maxillary obturator prostheses. J Prosthet Dent. $1989 ; 62: 205-212$.

[6] Martin JW, King GE. Framework retention for maxillary obturator prostheses. J Prosthet Dent. 1984; 51:669-672

[7] Barry H. Habib, DMD, MS, and Carl F. Driscoll, DMDFabrication of a closed hollow obturatorJ Prosthet Dent 2004; 91:383-385.

[8] McAndrew KS, Rothenberger S, Minsley GE: An innovative investment method for the fabrication of closed hollow obturator prosthesis. J Prosthet Dent 1998; 80:129-132.

[9] NidifferTj, ShipmanT H. The hollow bulb obturator for acquired palatal openings. J Prosthet Dent 1957; vol 7(1): 126-134

[10] Worley JL, Kneiejski ME. A method for controlling the thickness of hollow obturator prosthesis. J Prosthet Dent 1983; 50: 227-29.

[11] Holt RA Jr. A hollow complete lower denture. J Prosthet Dent 1981; 45: 452-54.

[12] Minsley GE, Nelson DR, Rothenberger SL: An alternative method for fabrication of a closed hollow obturator. J Prosthet Dent $1986 ; 55: 485-490$.

[13] HimamshiAggarwal, Sunit K Jurel, Raghuwar D. Singh, Pooran Chand \&Pradeepkumar. Lost salt technique for severely resorbed alveolar ridges: An innovative approach.ContempClin Dent. 2012 Jul-Sep; 3(3): 352-355.

[14] Muaiyed M. Buzayan, MClinDent, Yusnidar T. Ariffin, NorsiahYunus. Closed Hollow Bulb Obturator-One-Step Fabrication: A Clinical Report.J of Prosthodont.2013;Oct;22(7):591-5

[15] Parel SM, LaFuente H. Single-visit hollow obturators for edentulous patients. J Prosthet Dent.1978; 40:426-429.

[16] Schneider A. Method of fabricating a hollow obturator. J Prosthet Dent. 1978; 40:351.

[17] El Mahdy AS: Processing a hollow obturator. J Prosthet Dent 1969; 22:682-686.

[18] McAndrew KS, Rothenberger S, Minsley GE: An innovative investment method for the fabrication of closed hollow obturator prosthesis. J Prosthet Dent 1998; 80:129-132.

[19] Tanaka Y, Gold HO, Pruzansky S. A simplified technique for fabricating a lightweight obturator. J Prosthet Dent. 1977; 38:638642 .

[20] H. Devlin, G.R. Barker. Prosthetic rehabilitation of the edentulous patient requiring a partial maxillectomy. J Prosthet Dent. 1992; 67(2):223-227.

[21] Kanazawa T, Yoshida H, furuya Y Sectional prosthesis with hollow obturator portion made of thin silicone layer over resin frame. J Oral Rehabil 2000sept 27(9):760-764.

\section{LEGENDS}

Figure 1: Pre- Operative View

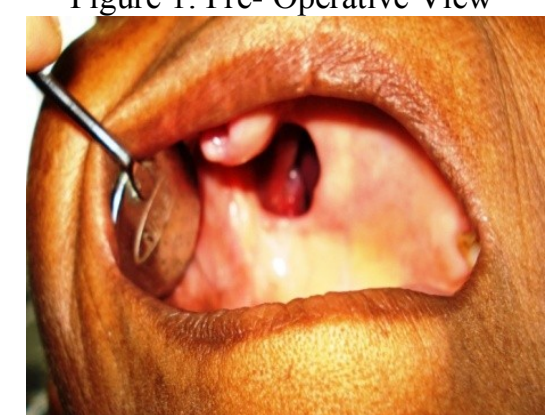

Figure 2: Master cast depicting the defect and blocked undercuts

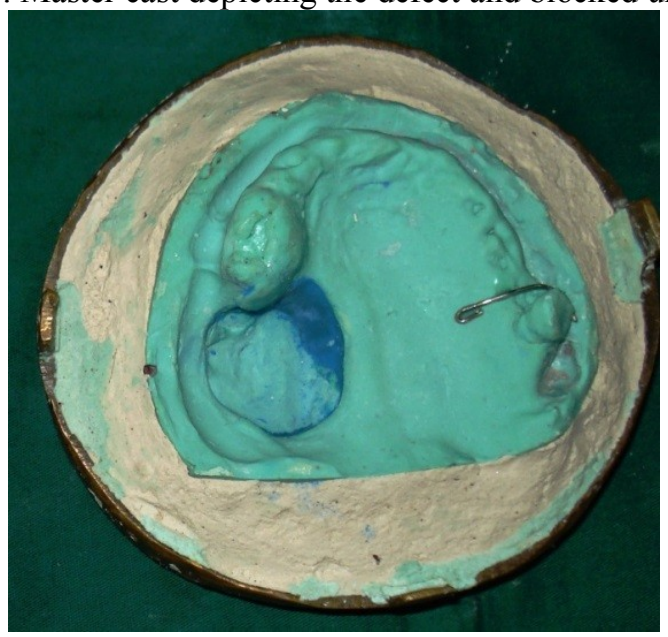


Figure 3: $\mathrm{NaCl}$ packed with silicone putty

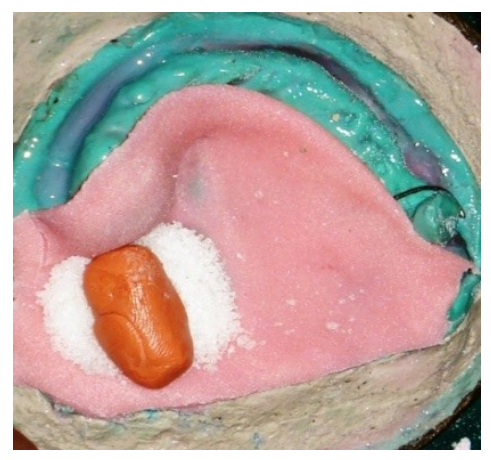

Figure 4: Layer of heat cure resin spread over the placed $\mathrm{NaCl} \&$ silicone putty

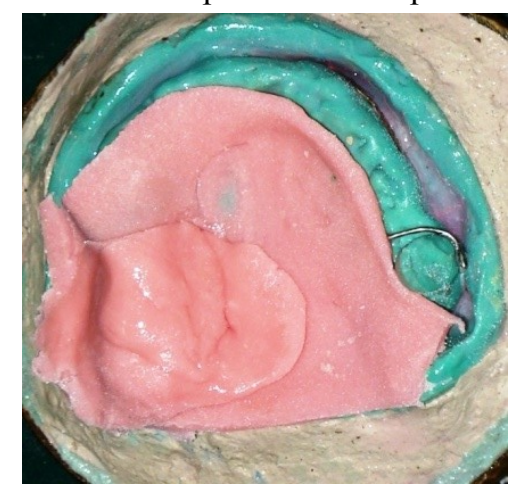

Figure 5: Created hole to retrieve silicone putty

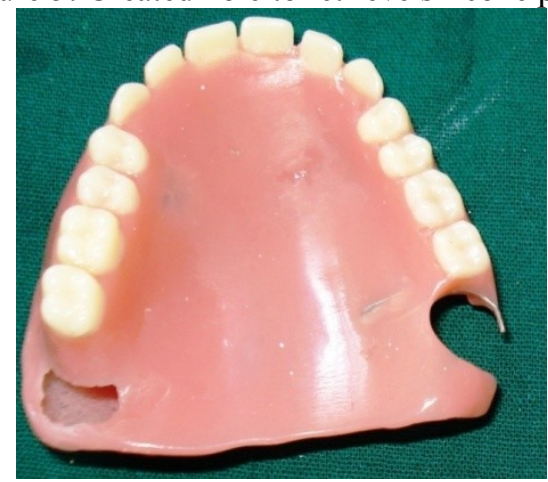

Figure 6: Intaglio surface

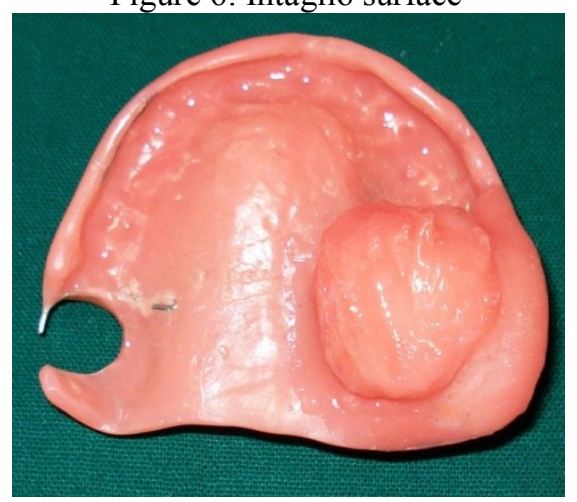


Figure 7: Post Operative View

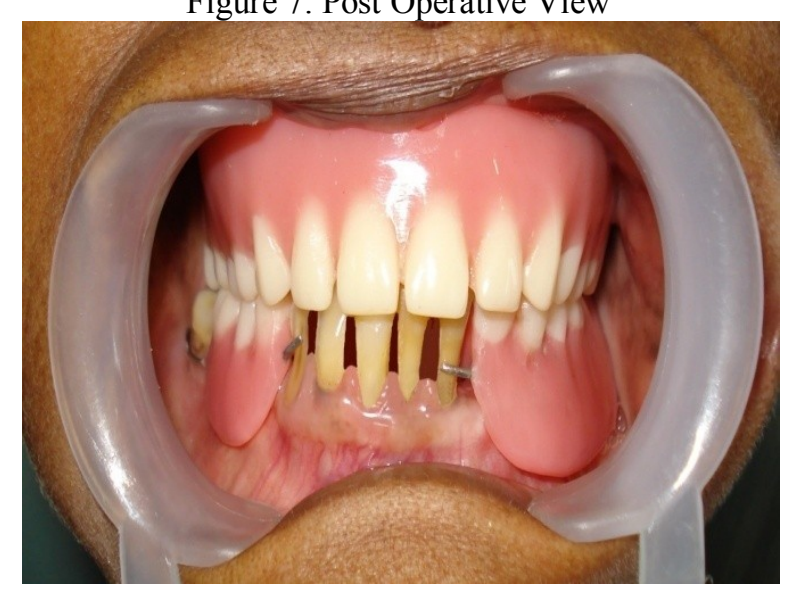

